\title{
Information gives hope
}

\author{
Mark Lesselroth describes how information and peer support helped him to accept that his vision \\ impairment could worsen
}

\section{Mark Lesselroth}

I was 37 years old when I visited an optometrist because I thought I might need reading glasses. What happened that day would change my life forever. It turned out I had narrow angle glaucoma and was six months away from becoming blind. The condition is sometimes called the "silent thief of the night" because you can go from having no symptoms to waking up completely blind.

Even if I followed all the advice given to me-taking eye drops and having surgery-I might still go blind. I was terrified at the prospect. Many people have told me that the possibility of losing your sight is one of the most anxiety provoking diagnoses you can receive. Now I can understand, as the diagnosis came as a total shock and fear set in instantly. Was I going to see my children grow up? Would I see my daughters walk down the aisle when getting married? How would I continue my work? I saw my life flashing before me.

\section{More questions than answers}

Within hours of the diagnosis I was referred to a specialist and was desperately looking for answers. I was given a leaflet, but what I wanted was a folder full of information on what might happen and whether I was going to go blind. I had lots of questions and not many answers. I wanted to take control of the glaucoma, but to do this I needed, and wanted, information.

I decided to take matters into my own hands and find out more. Who would the disease affect? What, if anything, was being done to help educate patients about the prognosis? What kind of treatments existed? Were there any support groups I could lean on, share stories with, and look for advice from? I found two and contacted them to find out more about what it was like to have this condition, what I could expect, and the potential outcomes and progression. Ultimately I started my own support group in Central New York because I realised I wasn't the only patient looking for answers.

\section{Getting the right amount of information}

I wanted health professionals to share all the information they had, and to be clear when they had no answers. When they acknowledged gaps in knowledge, it reassured me they weren't withholding information, which would have made me fear the worst. It would have helped to have a list of resources to take home after the diagnosis, to refer to when I was ready.

It was important for me to know that good information was available, and how and where it could be accessed. Lots of detailed, free information is available on glaucoma, which I wish I had known early in my diagnosis. Having the facts would have prevented feelings of loss and hopelessness. Knowing what could lie ahead, and the prospects for keeping my sight, would have been reassuring.

As with many other chronic conditions I need to take control of my health and be vigilant to changes-to monitor myself and report anything new to my health professional. To do this, I need to know everything about my condition, especially about the expected progression and treatments. Since my diagnosis I have helped other patients to find information through support groups and educational information from charities because I know how much this has helped me. My personal journey also paved the way to me reviving a company called BioPortUSA, the purpose of which is to identify innovative life science technologies for all medical conditions.

\section{Finding hope}

Accepting my condition was initially difficult. Having access to information about glaucoma and knowing what developments are being worked on gives me hope and peace of mind.

\footnotetext{
What you need to know

Knowing about the current evidence on disease progression and sharing it with patients can help them stay positive

- Let patients know there is hope

- Make patients aware of the resources available to them, including online support groups
} 


\section{Education into practice}

- What information resources could you share with this patient?

- Receiving a diagnosis with uncertainty over the progression can be overwhelming for patients. How can you identify how much information patients want and when?

- How could you introduce peer support to patients who want to learn more about the progression of the disease?
Competing interests: $\mathrm{ML}$ is chief executive officer of BioPortUSA and president of the Central New York chapter of the Glaucoma Foundation.

Provenance and peer review: Commissioned, based on an idea from the author; not externally peer reviewed.

Published by the BMJ Publishing Group Limited. For permission to use (where not already granted under a licence) please go to http://group.bmj.com/group/rights-licensing/ permissions 